\title{
TESTE DE TETRAZÓLIO PARA AVALIAÇÃO DA QUALIDADE FISIOLÓGICA EM SEMENTES DE GOIABEIRA-SERRANA (Acca sellowiana O. BERG BURRET) ${ }^{1}$
}

\author{
MARCELO BENEVENGA SARMENTO², ANA CAROLINA SILVEIRA DA SILVA ${ }^{3}$, \\ FRANCISCO AMARAL VILLELA ${ }^{4}$, KARINE LOUISE DOS SANTOS ${ }^{5}$, \\ LETÍCIA CANTILIANO PEREZ DE MATTOS ${ }^{6}$
}

\begin{abstract}
RESUMO- A goiabeira-serrana, espécie frutífera nativa do Sul do Brasil, vem mostrando- se promissora em termos ecológicos e comerciais. O trabalho objetivou avaliar a qualidade fisiológica de dois lotes de sementes de goiabeira-serrana por meio do teste de tetrazólio. O experimento foi dividido em duas etapas. Na primeira, os lotes foram submetidos aos testes de germinação, índice de velocidade de germinação, tempo médio de germinação, emergência em casa de vegetação, índice de velocidade de emergência de plântulas em casa de vegetação, tempo médio de emergência e comprimento de parte aérea. Na segunda, foi realizado o teste de tetrazólio nas concentrações de 0,5 e 1,0, e tempos de embebição ( $2 \mathrm{~h}$ e 4 h). O tratamento 0,5 TZ 4 h obteve $73 \%$ de sementes viáveis (lote 2007). Para o lote 2008, não houve diferenças entre os tratamentos. $\mathrm{O}$ teste de germinação apresentou correlação positiva para os tratamentos $0,5 \mathrm{TZ} 2 \mathrm{~h}$ e $1 \mathrm{TZ} 2 \mathrm{~h}$. Para a emergência de plântulas em casa de vegetação, houve correlação positiva para o tratamento $0,5 \mathrm{TZ} 2 \mathrm{~h}$. O teste de tetrazólio permitiu a classificação dos lotes em quatro níveis de viabilidade, confirmando a eficiência do teste na avaliação da viabilidade de sementes de goiabeira-serrana.
\end{abstract}

Termos para indexação: feijoa, goiabeira nativa, viabilidade, germinação.

\section{TETRAZOLIUM TEST TO EVALUATE PHYSIOLOGICAL QUALITY OF BRAZILIAN GUAVA SEEDS (Acca sellowiana O. BERG BURRET)}

\begin{abstract}
Brazilian guava, native fruit tree from Southern Brazil, has become relevant due to its potencial use as ecological and comercial. This article aims evaluate the physiological quality of Brazilian guava seeds by tetrazolium test. The work was divided in two parts. In the first, both lots were submitted to the germination test, index of speed germination, mean time of germination, emergency of seedlings in greenhouse, mean time of emergency and shoot length of seedlings. In the second part it was performed the tetrazolium test. Two concentrations of tetrazolium were used $(0,5$ e 1,0) and two times of imbibition $(2 \mathrm{~h} \mathrm{e} 4 \mathrm{~h})$. To the lot 2007 , the treatment $0,5 \mathrm{TZ} 4 \mathrm{~h}$ obtained $73 \%$ of viable seeds, otherwise, to the lot 2008 , the was no significant differences among treatments. For the germination test there has been positive correlation for $0,5 \mathrm{TZ} 2 \mathrm{~h}$ and $1 \mathrm{TZ} 2 \mathrm{~h}$ treatments. Emergency of seedlings in greenhouse was correlated only to $0,5 \mathrm{TZ} 2$ h. The Tetrazolium Test has allowed to rank the lots in four classes of viability, confirming the eficiency of the test to evaluate the viability of Brazilian Guava seeds.
\end{abstract}

Index terms: feijoa, native Brazilian Guava, viability, germination.

\footnotetext{
1(Trabalho 263-12). Recebido em: 29-10-2012. Aceito para publicação em: 06-04-2013.

${ }^{2}$ Eng. Agr. Dr. Professor, Universidade Federal do Pampa, Campus Dom Pedrito. E-mail: marcelobs05@hotmail.com

${ }^{3}$ Eng. Agrônoma, Dra. Instituto Biotecnológico de Reprodução Vegetal-INTEC, URCAMP/Bagé. E-mail: acsilveiras@yahoo.com.br ${ }^{4}$ Dr. Professor Associado, UFPel- Faculdade de Agronomia Eliseu Maciel; E-mail: francisco.vilela@pq.cnpq.br

${ }^{5}$ Dra. Professora Adjunto, Universidade Federal de Santa Catarina/Campus Curitibanos. E-mail: karine.santos@ufs.br

${ }^{6}$ Bióloga, Especialista. Técnica de Laboratório da Universidade da Região da Campanha, URCAMP/Bagé. E-mail: leticiacantiliano@ yahoo.com.br
} 


\section{INTRODUÇÃO}

A goiabeira-serrana (Acca sellowiana (O. Berg) Burret), nativa do planalto meridional brasileiro e nordeste do Uruguai, é conhecida popularmente por goiabeira-do-mato, goiabeira-do-campo, ou feijoa, e no Uruguai como guayabo del país. A espécie vem despertando grande interesse econômico devido ao sabor exótico de seus frutos. Além disso, a goiabeira-serrana apresenta grande potencial de uso ornamental e paisagístico, e na recuperação de matas nativas e áreas degradadas.

Apesar da importância crescente da goiabeira-serrana tanto em termos ecológicos como econômicos, sobretudo em pequenas propriedades, na região da serra catarinense, praticamente inexistem estudos sobre a tecnologia de suas sementes e mudas. Nesse sentido, a avaliação da qualidade fisiológica torna-se de grande relevância.

Para avaliar a qualidade fisiológica da semente de forma mais rápida, Pinto et al. (2008) indicam o teste de tetrazólio, pois ele agiliza a tomada de decisão para a produção de mudas, objetivo final da tecnologia de sementes de espécies florestais.

Em espécies nativas da família Myrtaceae, são raros os trabalhos de pesquisa envolvendo o teste de tetrazólio. Masetto et al. (2009) avaliaram com eficiência a qualidade fisiológica de sementes de Eugenia pleurantha com o uso do teste, ao possibilitar a identificação de tecidos vivos, mortos e viáveis, em diferentes níveis, permitindo a classificação em viáveis e não viáveis e, ainda, em diferentes níveis de viáveis e não viáveis.

No caso de sementes de goiabeira-serrana, o teste de tetrazólio pode auxiliar na avaliação de sua viabilidade. Com base nessa premissa, o objetivo do trabalho foi avaliar a qualidade fisiológica e a potencialidade de uso do teste de tetrazólio para avaliar a viabilidade em sementes de goiabeira-serrana (Acca sellowiana (O. Berg) Burret) armazenadas em câmara fria.

\section{MATERIAL E MÉTODOS}

\section{Germoplasma Utilizado}

Foram utilizadas sementes de dois lotes de goiabeira-serrana (Acca sellowiana (O. Berg) Burret), tendo sido um coletado em abril de $2007 \mathrm{e}$ o outro em abril de 2008. As sementes eram procedentes do Banco Ativo de Germoplasma da Empresa de Pesquisa Agropecuária e Extensão Rural de Santa Catarina (Epagri), em São Joaquim-SC, coletadas de frutos de clones de genótipos de progênies de polinização livre.

\section{Pós-colheita de sementes}

Frutos maduros que haviam caído das plantas foram coletados e despolpados em água corrente, com auxílio de peneiras. As sementes obtidas foram secas à sombra pelo período de sete dias e mantidas em câmara fria a $4^{\circ} \mathrm{C}$ e umidade relativa de $65 \%$, até maio de 2011, quando foram avaliados o teor de água, teste de tetrazólio, teste de germinação e emergência em casa de vegetação.

\section{Teor de Água}

Foram utilizadas duas repetições de 60 sementes. Os testes foram realizados em estufa sob temperatura de $105 \pm 3^{\circ} \mathrm{C}$, durante 24 horas. Os resultados foram expressos em porcentagem com base no peso úmido das sementes.

\section{Teste de Tetrazólio}

As sementes foram imersas em água destilada por 12 horas, a $30^{\circ} \mathrm{C}$. Pré-testes realizados (dados do autor, não publicados) indicaram o seccionamento longitudinal, seguido da remoção do tegumento, como método mais adequado. Após o corte longitudinal, as sementes foram colocadas em copos plásticos de $50 \mathrm{ml}$ e imersas em solução de tetrazólio a $40^{\circ} \mathrm{C}$, no escuro.

Utilizaram-se as concentrações da solução de tetrazólio de 0,5 e $1 \%$ e tempos de embebição de $2 \mathrm{~h}$ e $4 \mathrm{~h}$, com quatro repetições de dez sementes.

Após os respectivos períodos de embebição, as sementes foram lavadas em água corrente e avaliadas individualmente com o auxílio de lente de aumento. As duas metades foram individualmente examinadas quanto à viabilidade e, de acordo com a extensão, intensidade dos tons avermelhados, presença de áreas brancas leitosas, aspecto dos tecidos e localização destas colorações em relação às áreas essenciais ao crescimento.

Os embriões avaliados foram separados em categorias de viabilidade, de acordo com os diferentes padrões de coloração que variaram do vermelho intenso até o branco.

O padrão utilizado para a classificação dos níveis de viabilidade foi baseado no proposto por Masetto et al. (2009), para Eugenia pleuranta (Myrtaceae), adaptado para a espécie $A$. sellowiana. Foram estabelecidos os seguintes níveis de viabilidade com base na coloração e firmeza dos tecidos: Viável A $100 \%$ de viabilidade e tecidos firmes; Viável B - mais que $50 \%$ dos tecidos coloridos com tecidos firmes; Inviável C - mais que $50 \%$ dos tecidos não coloridos e tecidos internos amolecidos, e Inviável D - 100\% dos tecidos não coloridos. 


\section{Teste de Germinação}

A duração do teste estendeu-se por 36 dias após a semeadura (DAS) e foi conduzido com quatro repetições de 20 sementes, em papel germiteste e germinador tipo BOD. O fotoperíodo foi de $16 \mathrm{~h}$. Considerou-se germinada a plântula que apresentou raiz principal igual ou maior que dois milímetros. Juntamente com o teste de germinação, também foram avaliados o comprimento total da plântula (aos 36 DAS), o índice de velocidade de germinação, conforme Maguire (1964), e o tempo médio de germinação, de acordo com a fórmula de Edmond e Drapala (1958).

\section{Emergência em Casa de Vegetação}

$O$ teste de emergência em casa de vegetação teve duração de 98 dias e foi conduzido em bandejas de isopor com 72 células, sendo seis repetições por tratamento. O substrato utilizado foi o Tropstrat ${ }^{\mathrm{TM}}$. Neste teste, também foram avaliados o índice de velocidade de emergência (MAGUIRE, 1964) e o tempo médio de emergência (EDMOND; DRAPALA, 1958). Aos 98 dias após o início da emergência, avaliou-se, também, o comprimento da parte aérea, medindo-se com régua milimetrada do colo da plântula à ponta do ápice caulinar.

\section{Procedimento estatístico}

O experimento foi instalado em delineamento inteiramente casualizado. Os dados obtidos nos testes de tetrazólio, teste de germinação e emergência em casa de vegetação foram submetidos à análise de variância.

Todas as variáveis avaliadas foram submetidas aos testes de normalidade dos dados e de homogeneidade das variâncias e, posteriormente, submetidas à análise de variância. Constatando-se significância, as médias dos tratamentos foram comparadas pelo teste de Duncan, a 5\% de probabilidade.

Foi realizada análise de correlação linear simples de Pearson para o teste de germinação, emergência em casa de vegetação e teste de tetrazólio. O software utilizado nas análises foi o STATISTICA 10.0 (STATSOFT, 2011).

\section{RESULTADOS E DISCUSSÃO}

\section{Caracterização inicial dos lotes}

A Tabela 1 apresenta os dados de qualidade fisiológica para ambos os lotes de sementes de $A$. sellowiana. Observam-se diferenças significativas entre as sementes dos lotes 2007 e 2008 em relação ao teste de germinação, emergência em casa de vegetação e tempo médio de emergência.
O lote de sementes coletadas em abril de 2008 apresentou $72 \%$ de germinação, enquanto as sementes do lote coletado em abril de 2007 tiveram $52 \%$ de germinação, evidenciando a superioridade das sementes do lote de 2008 (Tabela 1). A emergência em casa de vegetação é um consistente indicador do potencial da semente em produzir mudas de alta qualidade.

Com relação ao tempo médio de emergência (Tabela 1), os lotes apresentaram, respectivamente, 82 e 73 DAS, para 2007 e 2008, confirmando a maior qualidade fisiológica do lote de 2008. O tempo médio de emergência reflete as características genéticas adaptativas de cada espécie ou genótipo, bem como $o$ vigor de um lote de sementes. A espécie goiabeira-serrana mostrou-se de lenta germinação, com base nos dados preliminares não publicados, confirmando o que já fora reportado para outras espécies silvestres.

Para as variáveis Índice de Velocidade de Germinação (IVG), Tempo Médio de Germinação (TMG), Índice de Velocidade de Emergência de plântulas em casa de vegetação (IVEC) e Comprimento da Parte Aérea (CPA), não houve diferenças significativas entre os lotes de sementes (Tabela 1). É possível que a diferença no grau de umidade tenha influenciado na diferença da qualidade fisiológica observada entre os lotes avaliados, embora a espécie estudada seja ortodoxa quanto ao comportamento fisiológico no armazenamento.

$\mathrm{O}$ armazenamento em câmara fria a $4^{\circ} \mathrm{C} \mathrm{e}$ umidade relativa de $60 \%$, utilizado no Banco Ativo de Germoplasma de goiabeira-serrana da EPAGRI, Unidade de São Joaquim-SC, foi eficiente na manutenção da qualidade fisiológica em níveis aceitáveis.

\section{Teste de Tetrazólio}

Na Tabela 2, são apresentados os dados do teste de tetrazólio para as sementes dos lotes 2007 e 2008. Observaram-se diferenças significativas entre as concentrações e tempos utilizados para as sementes do lote de 2007.

Em relação ao lote de 2008, não houve diferenças entre os tratamentos. As sementes deste lote obtiveram viabilidade de $70 \%$ em todos os tratamentos (Tabela 2), confirmando a alta qualidade fisiológica deste lote de sementes mesmo após três anos de armazenamento em câmara fria, a $4{ }^{\circ} \mathrm{C}$, e umidade relativa de $60 \%$. Para esse lote, os dados obtidos nos tratamentos com o tetrazólio estão coerentes com os resultados do teste de germinação e da emergência de plântulas em casa de vegetação (Tabela 1).

A solução de tetrazólio a $0,5 \%$, combinada com o tempo de quatro horas, permitiu, em ambos os lotes, a obtenção de viabilidade acima de 73\% (2007) 
e 75\% (2008) (Tabela 2). Para as sementes do lote de 2007, esse valor é discordante do valor obtido para a germinação (58\%), porém concorda com os $73 \%$ da emergência em casa de vegetação (Tabela 1). O reduzido valor da germinação para este lote pode ser explicado pela infestação de fungos que pode ter interferido na avaliação do teste. Na emergência em casa de vegetação, não houve contaminação por fungos, e as plântulas tiveram adequado desenvolvimento inicial.

O tempo de duas horas para as sementes do lote de 2007, em ambas as concentrações $(0,1$ e 0,5$)$, apresentou 35 e $38 \%$ de viabilidade, respectivamente (Tabela 2). Esse lote de sementes mostrou-se com menor qualidade fisiológica que o lote de 2008. Outra possível explicação é que tenha havido subestimação dos valores de viabilidade pelo insuficiente tempo de coloração das sementes.

Empregando o teste de tetrazólio em Eugenia pleurantha (Myrtaceae), Masetto et al. (2009) não observaram diferenças entre as concentrações utilizadas. Todavia, a solução de tetrazólio a $0,5 \%$ e o tempo de 12 horas dificultaram a interpretação das classes de viabilidade, devido à formação de coloração escura bastante uniforme nos embriões. $\mathrm{Na}$ presente pesquisa, o tempo de duas horas de embebição foi suficiente para permitir a coloração e a avaliação em ambos os lotes.

Para sementes de Poecilanthe parviflora Bentham, Valadares et al. (2009) obtiveram coloração adequada com tetrazólio, com duas horas de embebição. Nos lotes de menor qualidade fisiológica, pode ser necessário um tempo adicional de embebição para permitir a adequada coloração. Conforme a Tabela 2, esse fato pode ter ocorrido no tratamento a $0,5 \mathrm{TZ} 4 \mathrm{~h}$, superestimando a qualidade fisiológica do lote de 2007.

Em trabalho com a espécie arbórea leucena, Costa e Santos (2010) relataram que a solução de tetrazólio a $1 \%$ promoveu coloração muito intensa das sementes, dificultando a interpretação do teste.

Os resultados alcançados no presente estudo concordam com as indicações para as espécies em geral, definidas nas Regras para Análise de Sementes (BRASIL, 2009), que recomendam concentrações de 0,5 até $1,0 \%$ da solução de tetrazólio e períodos de coloração de seis a 24 horas. É possível que, nesta pesquisa, a remoção do tegumento das sementes tenha favorecido a absorção mais rápida da solução de tetrazólio pelos tecidos adjacentes.

Melhor visualização da coloração dos tecidos de sementes de coquinho-azedo (Butia capitata (Mart.) Becc) foi obtida por Fernandes et al. (2007), com embebição em solução de tetrazólio a $0,5 \%$ de concentração, por quatro horas. Trabalhando com sementes de Parkia velutina Benoist (Mendes et al., 2009) e de Sesbania virgata (Camargos et al., 2008) também foi observada, para avaliar a viabilidade das sementes dessas espécies, a melhor combinação foi a concentração de $0,5 \%$ do sal de tetrazólio no período de embebição de duas horas.

Trabalhando com sementes de capim-pé-de-galinha (Eleusine coracana L.) (Poaceae), Maia et al. (2011) utilizaram, com eficiência para a avaliação da viabilidade, a concentração do sal de tetrazólio a $0,5 \%$, por duas horas e trinta minutos.

Para avaliar a viabilidade de sementes de palmeira-macaúba (Acrocomia aculeata L.), Ribeiro et al. (2010) também verificaram superioridade da concentração de tetrazólio a $0,5 \%$ e tempo de embebição de $4 \mathrm{~h}$, a $35^{\circ} \mathrm{C}$.

Sugere-se, por motivo de economia de reagentes, a utilização da solução de tetrazólio com concentração de $0,5 \%$ e tempo de exposição de duas horas. Esta combinação de concentração de solução e período de imersão das sementes na solução do sal de tetrazólio permitiu intensidade e uniformidade de coloração no tecido embrionário. Além disso, possibilitou melhor separação entre os padrões de coloração apresentados, refletindo com maior clareza os resultados, tanto do teste de germinação como da emergência em casa de vegetação (Tabela 1).

As sementes de goiabeira-serrana possuem germinação lenta e desuniforme, portanto o emprego do teste de tetrazólio poderia otimizar a previsão da viabilidade das sementes.

Por se tratar de um teste rápido na análise de sementes, demandando menor tempo na obtenção de resultados, em comparação ao teste de germinação, o teste de tetrazólio vem sendo recomendado para avaliação de sementes de várias espécies florestais, como: Astronium graveolens (guaritá); Peltophorum dubium (canafístula) (OLIVEIRA et al., 2005); Gleditschia amorphoides (sucará) (FOGAÇA et al., 2006), e Lafoensia pacari (mangaba-brava) (MENDONÇA et al., 2006).

\section{Classificação dos Níveis de Viabilidade}

Na Figura 1, está representada a classificação dos níveis de viabilidade estabelecidos no teste de tetrazólio para sementes de goiabeira-serrana. Foram consideradas as seguintes características como critérios para a classificação das sementes: 1- tecidos com coloração vermelha brilhante, uniforme ou rósea vivo, típicos de tecido sadio (viável); 2- tecidos com coloração branca, amarelada ou creme, característicos de tecidos mortos; 3- tecidos com coloração vermelho-escura intensa, indicativos de tecidos em 
deterioração, e 4- percentual de tecidos coloridos ou não coloridos.

A partir da coloração apresentada pelos embriões, foram definidas duas categorias de sementes viáveis e duas categorias de sementes não viáveis (Figura 1). Considerou-se a descrição das classes de viabilidade preconizadas em material e métodos.

Os padrões de tonalidade observados na secção interna das sementes variaram do branco-creme (semente morta) ao vermelho-forte (semente viável). A coloração branca foi encontrada, principalmente, na região da radícula e raramente nos cotilédones.

Para a espécie Eugenia pleurantha, Masetto et al. (2009) estabeleceram cinco classes de viabilidade. A definição do número de classes vai depender da coloração das sementes, características morfológicas da espécie e dos tratamentos aplicados, sendo que, para diferentes espécies, distintos níveis de classes podem ser propostos. Embora a presente pesquisa tenha como base a proposta de Masetto et al. (2009), foi possível definir com clareza e segurança apenas quatro classes.

Correlação do Teste de Tetrazólio, Teste de Germinação e Emergência em Casa de Vegetação

Os valores dos coeficientes de correlação entre os resultados dos testes de tetrazólio, germinação e emergência em casa de vegetação estão apresentados na Tabela 3.

Para o teste de germinação, houve correlação positiva para os tratamentos $0,5 \mathrm{TZ} 2 \mathrm{~h}(\mathrm{r}=0,85) \mathrm{e}$ $1,0 \mathrm{TZ} 2 \mathrm{~h}(\mathrm{r}=0,79)$. Para a emergência em casa de vegetação, houve correlação positiva apenas para o tratamento $0,5 \mathrm{TZ} 2 \mathrm{~h}(\mathrm{r}=0,71)$.

Correlação positiva e significativa entre esses testes e o teste de tetrazólio também foi observada por Costa e Santos (2010) em sementes florestais para sementes de leucena. Em espécies herbáceas, correlação positiva e significativa entre esses testes também foi encontrada em abobrinha (BARROS et al., 2005) e melancia (NERY et al., 2007).

Embora os resultados obtidos geralmente reflitam a subjetividade inerente deste tipo de avaliação, há relevantes estudos que o correlacionam com os testes de germinação e emergência em casa de vegetação. Nesse sentido, pode-se avaliar a qualidade fisiológica das sementes de goiabeira-serrana de forma rápida, considerando-se a lenta e desuniforme germinação e a emergência das plântulas da espécie.

Esses resultados confirmam a possibilidade de utilização do teste de tetrazólio para avaliar a viabilidade de sementes de goiabeira-serrana, conforme já observado em diversas espécies florestais, como imbuia (Ocotea porosa) e Eugenia pleurantha (MASETTO et al., 2009); Poecilanthe parviflora Bentham (VALADARES et al., 2009), leucena (COSTA; SANTOS, 2010), dentre outros.

A interpretação dos resultados obtidos neste trabalho permite inferir que o teste de tetrazólio pode ser utilizado com eficiência na determinação da viabilidade de sementes de goiabeira-serrana.

TABELA 1-Atributos da qualidade fisiológica de

dois lotes de sementes de goiabeira-serrana (Acca sellowiana (O.Berg) Burret) armazenados em câmara fria $\left(4^{\circ} \mathrm{C}\right.$ e $65 \%$ UR).

\begin{tabular}{lcccccccc}
\hline Lotes & U (\%) & G (\%) & IVG & TMG & IVEC & ECV (\%) & TME & CPA (cm) \\
\hline $\mathbf{2 0 0 7}$ & 6,2 & $52 \mathrm{~b}$ & $0,421 \mathrm{a}$ & $22,4 \mathrm{a}$ & $0,075 \mathrm{a}$ & $58 \mathrm{~b}$ & $82 \mathrm{a}$ & $2,52 \mathrm{a}$ \\
$\mathbf{2 0 0 8}$ & 12,1 & $72 \mathrm{a}$ & $0,424 \mathrm{a}$ & $22,8 \mathrm{a}$ & $0,101 \mathrm{a}$ & $72 \mathrm{a}$ & $73 \mathrm{~b}$ & $2,56 \mathrm{a}$ \\
\hline $\mathbf{C V}(\boldsymbol{\%})$ & - & $\mathbf{2 2}$ & $\mathbf{9}$ & $\mathbf{5}$ & $\mathbf{2 2}$ & $\mathbf{2 0}$ & $\mathbf{7}$ & $\mathbf{8}$ \\
\hline
\end{tabular}

Médias seguidas da mesma letra, nas colunas, não diferem pelo teste de Duncan, a 5\%.

Legenda: U- grau de umidade; G- teste de germinação; IVG- índice de velocidade de germinação; TMG- tempo médio de germinação (DAS); IVEC- índice de velocidade de emergência em casa de vegetação; ECV- emergência em casa de vegetação; TME- tempo médio de emergência (DAS); CPA- comprimento de parte aérea de plântula $(\mathrm{cm})$. 
TABELA 2- Porcentagem de sementes viáveis (SV) de goiabeira-serrana (Acca sellowiana (O.Berg) Burret), de dois lotes de sementes armazenados em câmara fria $\left(4{ }^{\circ} \mathrm{C}\right.$ e $65 \%$ UR) e avaliados pelo teste de tetrazólio (TG).

\begin{tabular}{ccc}
\hline Tratamento & 2007- SV (\%) & 2008- SV (\%) \\
\hline $\mathbf{0 , 5}$ TZ 2h & $35 \mathrm{c}$ & $70 \mathrm{a}$ \\
$\mathbf{0 , 5}$ TZ 4h & $73 \mathrm{a}$ & $75 \mathrm{a}$ \\
$\mathbf{1 , 0}$ TZ 2h & $38 \mathrm{c}$ & $83 \mathrm{a}$ \\
$\mathbf{1 , 0}$ TZ 4h & $57 \mathrm{~b}$ & $70 \mathrm{a}$ \\
\hline CV (\%) & $\mathbf{1 5}$ & $\mathbf{8}$ \\
\hline
\end{tabular}

Médias seguidas de mesma letra, nas colunas, não diferem pelo teste de Duncan, a 5\%.

TABELA 3 - Coeficientes de correlação linear simples de Pearson (r) entre os resultados do teste de tetrazólio (TZ) e os dos testes de germinação (TG) e emergência de plântulas em casa de vegetação (ECV), em sementes de Acca sellowiana (O.Berg) Burret).

\begin{tabular}{ccclc}
\hline Parâmetros & $\mathbf{0 , 5}$ TZ $\mathbf{~ h}$ & $\mathbf{0 , 5}$ TZ $\mathbf{4 h}$ & $\mathbf{1 ~ T Z ~} \mathbf{~ h}$ & $\mathbf{1 ~ T Z ~} \mathbf{4 h}$ \\
\hline TG & $0,85^{*}$ & 0,50 & $0,79^{*}$ & 0,42 \\
ECV & $0,71^{*}$ & 0,15 & 0,51 & 0,28 \\
\hline
\end{tabular}

* Correlação significativa, ao nível de 5\%.

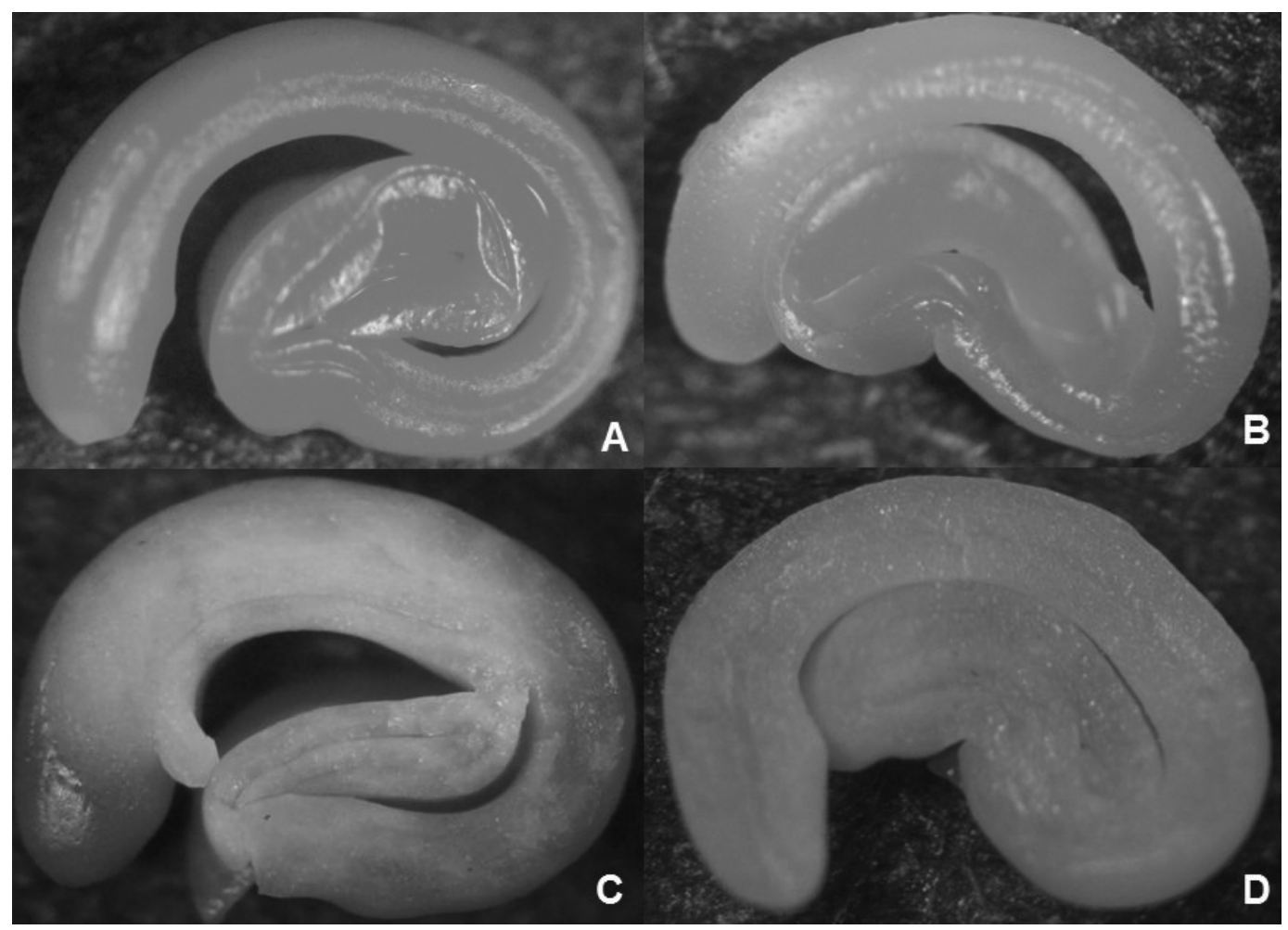

FIGURA 1- Classificação dos níveis de viabilidade pelo teste de tetrazólio (TZ) em sementes de goiabeiraserrana (Acca sellowiana (O.Berg) Burret): Viável A- 100\% de viabilidade e tecidos firmes; Viável B- mais que 50\% dos tecidos coloridos com tecidos firmes; Inviável C- mais que 50\% dos tecidos não coloridos e tecidos internos amolecidos, e Inviável D- 100\% dos tecidos não coloridos. 


\section{CONCLUSÕES}

1- O teste de tetrazólio permite, para sementes de goiabeira-serrana, o estabelecimento de diferentes níveis de viabilidade, com base na coloração e firmeza dos tecidos.

2- A utilização da solução de tetrazólio a $0,5 \%$, por duas horas, a $40^{\circ} \mathrm{C}$, é eficiente para a coloração de sementes de goiabeira-serrana.

3- Há correlação significativa entre o teste de tetrazólio e os testes de germinação e emergência em casa de vegetação, indicando ser este teste eficiente na avaliação da viabilidade de sementes de goiabeira-serrana.

\section{REFERÊNCIAS}

BARROS, D. I.; DIAS, D. C. F. S.; BHERING, M. C.; DIAS, L. A. S.; ARAÚJO, E. F. Uso do teste de tetrazólio para avaliação da qualidade fisiológica de sementes de abobrinha. Revista Brasileira de Sementes, Londrina, v.27, n.2, p.165-171, 2005.

CAMARGOS, V. N.; CARVALHO, M. L. M.; ARAÚJO, D. V.; MAGALHÃES, F. H. L. Superação de dormência e avaliação da qualidade de sementes de Sesbania virgata. Ciência e Agrotecnologia, Lavras, v.32, n.6, p.1858-1865, 2008.

COSTA, C. J.; SANTOS, C. P. dos. Teste de tetrazólio em sementes de leucena. Revista Brasileira de Sementes, Londrina, v. 32, n. 2, p. 066-072, 2010.

EDMOND, J. B.; DRAPALA, W. J. The effects of temperature, sand and soil, and acetone on germination of okra seed. Proceedings of the American Society Horticultural Science, Alexandria, n. 71, p. 428434, 1958.

FERNANDES, R. C.; MAGALHÃES, H. M.; LOPES, P. S. N.; BRANDÃO JÚNIOR, D. S.; FERNANDES, R. C.; GOMES, J. A. O.; PAULINO, M. A. O.; CARNEIRO, P. A. P. Elaboração da metodologia de aplicação do teste de tetrazólio para avaliação da viabilidade das sementes de coquinhoazedo (Butia capitata (Mart.) Becc). Revista Brasileira de Agroecologia, Cruz das Almas, v.2, n.2, p.1004-1007, 2007.

FOGAÇA, C. A.; ZUCARELI, C.; MALAVASI, M. M.; ZUCARELI, C; MALAVASI, U. C. Aplicação do teste de tetrazólio em sementes de Gleditschia amorphoides Taub. Caesalpinaceae. Revista Brasileira de Sementes, Lavras, v. 28, n. 3, p.101107, 2006.
MAIA, F. C.; CERVIERI FILHO, E. C.; GRIMM, H.; MAIA, M. de S.; FURTADO, L. Proposta metodológica para o teste de tetrazólio em sementes de Eleusine coracana L. Gaertn. Revista Científica Rural, URCAMP, Bagé, v.13, n.1, p.207-21.2011.

MAGUIRE, J. D. Speed of germination-aid in selection and evaluation for seedling emergence and vigor. Crop Science, Madison, v.2, n.1, p.176177,1964

MASETTO, T. E.; DAVIDE, A. C.; FARIA, J. M. R.; SILVA, E. A. A. da; REZENDE, R. K. S. Avaliação da qualidade de sementes de Eugenia pleurantha (Myrtaceae) pelos testes de germinação e tetrazólio. Agrarian, Dourados, v.2, n.5, p.33-46. 2009.

MENDES, A. M. da S.; BASTOS, A. A.; MELO, M. G. G. Padronização do teste de tetrazólio em sementes de Parkia velutina Benoist (LeguminosaeMimosoideae). Acta Amazonica, Manaus, v.39, n.4, p.823-828, 2009.

MENDONÇA, E. A. F.; COELHO, M. F. B.; LUCHESE, M. Teste de tetrazólio em sementes de mangaba-brava (Lafoensia pacari St.-Hil.Lythraceae). Revista Brasileira de Plantas Medicinais, Botucatu, v. 8, n. 2, p. 33 - 38, 2006.

NERY, M. C.; CARVALHO, M. L. M.; OLIVEIRA, L. M. Teste de tetrazólio para avaliação da qualidade fisiológica de sementes de melancia. Semina, Passo Fundo, v.28, n.3, p.365-372, 2007.

OLIVEIRA, L. M.; CARVALHO, M. L. M.; DAVIDE, A. C. Teste de tetrazólio para avaliação da qualidade de sementes de Peltophorum dubium (Sprengel) Taubert Leguminosae Caesalpinioideae. Cerne, Lavras, v. 11, n. 2, p. 159 - 166, 2005.

RIBEIRO, L. M.; GARCIA, Q. S.; OLIVEIRA, D. M. T.; NEVES, S. C. Critérios para o teste de tetrazólio na estimativa do potencial germinativo em macaúba. Pesquisa Agropecuária Brasileira, Brasília, v.45, n.4, p.361-368, 2010.

STATSOFT. Statistica for Windows [Computer program manual]. Versão 10.0. Tulsa: StatSoft. Disponível em: $<\underline{\text { http: } / / \text { www.statsoft.com }>\text {. Acesso }}$ em: 25 maio 2011.

VALADARES, J.; PAULA, R. C. de.; MÔRO, F. V. Germinação, desenvolvimento de plântulas e teste de tetrazólio em Poecilanthe parviflora Bentham (Fabaceae-Faboideae). Científica, Jaboticabal, v.37, n. 1, p.39 - 47, 2009. 